\title{
La crítica anti-utilitarista en el Norte y su importancia para el avance del pensamiento poscolonial en las sociedades del Sur
}

\author{
Paulo Henrique Martins*
}

\section{Resumen}

Nuestra reflexión en este artículo se basa en dos tesis complementarias: una epistemológica y otra epistémica. La epistemológica propone haber una conexión estrecha entre los estudios poscoloniales y descoloniales - que objetivan revalorar las tradiciones, luchas y posibilidades sociohistóricas de las sociedades del Sur -, y los estudios anti-utilitaristas que critican el neoliberalismo y la mercantilización del mundo promovido por las sociedades del Norte. La tesis epistémica, por su parte, sugiere que el avance simultáneo de la crítica teórica en las tres últimas décadas en el Sur y el Norte es producida por dislocamientos progresivos y cada vez más acelerados del imaginario de la modernidad, desde la mirada eurocéntrica para una mirada mundialocéntrica.

Palabras-clave: poscolonialidad, descolonialidad, anti-utilitarismo, sociología.

\section{Introducción}

M parece interesante empezar nuestra reflexión con una pregunta: ¿qué grado de interacción existe en los llamados estudios poscoloniales, que cuestionan la modernidad eurocéntrica y que buscan organizar un pensamiento del Sur, y los llamados estudios anti-utilitaristas que interrogan la teoría crítica moderna desde el Norte? La pregunta es amplia y favorece diversas interpretaciones. Hay los que no entienden haber interacción y que creen en una ruptura epistemológica entre Sur y Norte, como lo propone

Profesor titular de la Universidade Federal de Pernambuco (Recife - Brasil) e Vice-presidente de ALAS. Correo electrónico: pahem@terra.com.br. 
W. Mignolo (2008). En el lado contrario, hay los que entienden que esa interacción es orgánica y que el avance de la teoría crítica se hace de modo complementario en el Norte y en el Sur (DUSSEL, 2005; SANTOS, 2008). Nosotros nos posicionamos al lado de esa segunda línea de interpretación. En esa dirección, vamos a intentar en este texto profundizar algunos aspectos de los nexos que existen entre el avance de la critica descolonial y el avance de la crítica anti-utilitarista para la creación de una nueva epistemología y una nueva sociología de fronteras en esto momento.

Desde luego, es igualmente importante señalar que la búsqueda de nexos no significa que las antiguas fronteras nacionales quedan borradas, sino que las zonas de contacto, de organización de la cultura y de construcción del conocimiento quedan más abiertas y rápidas, favoreciendo, lo que es decisivo, una configuración de poder plural y diversificado. Así, las tareas que los especialistas académicos críticos se proponen a cada lado de la frontera están condicionadas por las experiencias cognitivas y prácticas de cada situación histórico-cultural y por las particularidades de los campos del conocimiento. Así, si en el Sur el pensamiento descolonial interroga teorías poscoloniales tradicionales prisioneras de la ideología del desarrollo, como la teoría estructuralista y la teoría de la dependencia, en el Norte hay otros marcos interpretativos a interrogar. En Europa, la critica anti-utilitarista y posestructuralista revisa la teoría crítica moderna, como la estructuralista y la marxista historicista, desde la crítica del universalismo cultural y económico que borra los factores culturales.

Nuestra reflexión en este artículo se basa entonces en dos tesis complementarias: una epistemológica y otra epistémica. La epistemológica propone haber una conexión estrecha entre los estudios poscoloniales y descoloniales - que objetivan revalorar las tradiciones, luchas y posibilidades socio-históricas de las sociedades del Sur -, y los estudios anti-utilitaristas que critican el neoliberalismo y la mercantilización del mundo promovido por las sociedades del Norte. Así, no se puede hablar de la crítica descolonial en Latinoamérica sin referencia a los "postcolonials studies", a los "subalterns studies", o a los "gender studies" en Inglaterra, sin referencia a Foucault, Derrida y Deleuze en Francia o sin revisar a 
Marx. El avance de la teoría crítica en un lado, en el Sur, se hace en paralelo a los cambios de la teoría en el otro lado, en el Norte.

Según nuestra hipótesis, los giros epistemológicos en curso tienen orígenes diversas definidas por la colonización, pero articuladas por una globalización que es producida en el espacio de la política y de la traducción cultural y linguística, lo cual se plantea desde los orígenes de la modernidad europea. En el Sur, el giro es conducido desde la praxis anticolonial y desde la crítica poscolonial que nació de la reacción contra la subalternidad jerárquica; en el Norte, el giro es producido desde el avance de la crítica anti-utilitarista, sobre todo sociológica, que pasa a interrogar la subalternidad no sólo desde la exploración económica sino desde los factores culturales y morales, como son pruebas las teorías del reconocimiento y del don en los últimos años.

La tesis epistémica, por su parte, sugiere que el avance simultáneo de la crítica teórica en las tres últimas décadas en el Sur y el Norte es producida por dislocamientos progresivos y cada vez más acelerados del imaginario de la modernidad, desde la mirada eurocéntrica para una mirada mundialocéntrica. La tesis epistémica plantea que la modernidad es un discurso que se genera, desde sus orígenes, por rupturas y desplazamientos entre las representaciones del pasado y del futuro, del este y del oeste, y entre los imaginarios diversos de la colonización que constituyen zonas linguiísticas de contacto. Cada imaginário apunta para una ecuación híbrida como son los casos de: latinización, indianización, occidentalización, orientalización, modernización entre otros. Me gusta la expresión dislocamiento epistémico como estrategia para plantear una metáfora y una situación que involucra al mismo tiempo las dos regiones de construcción de la colonialidad y de la modernidad, Sur y Norte ${ }^{1}$.

1 El término dislocamiento que J. Derrida desarrolla a partir de la discusión sobre la différence (DERRIDA, 1967; DERRIDA, LACLAU, MOUFFE, 1996) y que fue integrado en la crítica poscolonial por autores como S. Hall (1992; 2003) y H. Bhabha (2003), es interesante para designar rupturas epistémicas que acontecen simultáneamente en los diversos campos de conocimientos modernos: nacionales, corporativos, comunitarios o privados. De esa manera, tales rupturas se hacen desde el dislocamiento de experiencias intersubjetivas, significando el surgimiento de registros discursivos diferentes en donde había un registro primero y único. 
Y eso significa una articulación permanente entre los productores de conocimiento de las dos regiones, articulación que se plantea progresivamente en la coyuntura global con la ampliación de las interioridades y de lo que Dussel llamó de "exterioridades" (DUSSEL, 2005; GROSFOGUEL, 2010) para dar visibilidad teórica a los espacios de los colonizados. Por eso es importante que profundicemos la reflexión dialógica de los giros epistemológicos del Sur y del Norte.

Para mí, está claro, desde las experiencias de autores como F. Fanon y A. Memmi, que tuvieron experiencias de colonialidad intensas desde las fronteras imaginarias del Sur y del Norte, y también de mi experiencias en Latinoamérica y en Europa, que las dos regiones del conocimiento y del poder de las modernidades conocen ontologías diversas pero articuladas por traducciones y traductores en sus fronteras históricas, políticas, simbólicas y epistemológicas inter y transculturales. En esta dirección es necesario aclarar que Norte y Sur no son sólo puntos geográficos, administrativos, jurídicos y políticos, sino también lugares de producción de imaginarios sociales y culturales diversos que se mueven en paralelo. Sus cartografías de poder y de saber son redimensionadas desde las tensiones y conflictos que nascen en las fronteras compartidas del imaginario eurocéntrico com Asia, África o América Latina.

Esta valorización de los espacios de construcción del conocimiento "transmodernos" (DUSSEL, 2005) en los dos lados de las fronteras del imaginario de la mundialización, desde adentro y desde afuera, disloca la relación tradicional espacio-tiempo que basó la cartografía de la colonización y de los territorios de los Estados nacionales. Esa antigua cartografía fue producida por un saber colonizador organizado desde las fuerzas de la burguesía y de la cristiandad y que valoró la ideología del progreso, de la mercantilización y de la expropiación. Con la crítica descolonial producida desde las exterioridades ese marco tradicional es interrogado, lo que provoca el nacimiento de otro marco espaciotemporal que se impone sin eliminar el antiguo. Por consecuencia, son creados nuevos territorios transnacionales de organización de las experiencias de la vida cotidiana y nuevas modalidades de la acción colectiva y de la política. 
La superación de esas fronteras nacionales modernas esta cambiando las nociones de espacio y tiempo, permitiendo integrar nuevos horizontes cognitivos y emocionales en la producción de las experiencias individuales y colectivas, de género, de etnias, de sexualidad, entre otras. Desde la mirada europea, ser europeo, blanco y hombre del sexo masculino implicaba una enorme diferencia en la constitución de las jerarquías de respetabilidad a nivel mundial. Hoy, ser negro, mujer o aimara también marca diferencias y esta revalorización del diferente fundamenta la gran expansión actual de una nueva inteligencia universal respecto al ser humano y a la vida. O sea, las manifestaciones de la exterioridad cambian las representaciones del mundo desde fuera y desde dentro. Y la sombra del "bárbaro" pasa a cuestionar directamente la dominación colonial simultáneamente desde el Sur y desde el Norte. Pues si, por un lado, tenemos la emergencia de movimientos indígenas, por ejemplo, como prueba de los nuevos territorios de la praxis en el Sur, tenemos también las reacciones de los migrantes o las grandes movilizaciones urbanas en las grandes ciudades del Norte.

Desde los dos marcos relacionados, el epistemológico y el epistémico, sugerimos, así, una reflexión sobre el entendimiento de la crítica poscolonial no sólo desde los nuevos actores intelectuales del Sur, sino también desde los nuevos actores intelectuales en el Norte que están interrogando las epistemologías científicas. Para esa demostración voy a explorar la significación de la crítica anti-utilitarista para la sociología en Europa y como tal crítica conoció una inflexión importante en las últimas décadas. Más precisamente, a partir de la crisis del estructuralismo y de la emergencia de las tesis pos-estructuralistas en los años ochenta. Los tiempos pos-estructuralistas se cruzan con los tiempos de descolonialidad, para demostrar, como lo sugiere Oliver Kramsch (2010) que es imposible imaginar un espacio de enunciación descolonial sin el diálogo con los centros europeos ${ }^{2}$.

2 A la vez partimos de la convicción de que el territorio llamado Unión Europea necesita tanto de una epistemología decolonizadora y antiuniversalista como cualquier otra parte de mundo que enfrenta hoy el fantasma de una modernidad totalizadora y globalizante que ya no es reducible al espacio europeo... (KRAMSCH, 2010, p.257). 


\section{El utilitarismo como filosofía moral y la posición de la Sociología}

En primer lugar, es necesario señalar que la idea del antiutilitarismo es importante para comprender la idea de descolonialidad en América Latina aunque esta tesis no sea explícita. Pues el desarrollo del capitalismo fue organizado desde la asociación del proceso de acumulación del capital a través de la exploración del trabajo, y del proceso de negación de los "otros" (mujeres, negros, extranjeros, etc.) a través de la subalternación cultural y moral.

\section{El pensamiento latinoamericano y el utilitarismo}

Una pregunta para empezar: ¿porqué la palabra utilitarismo no es muy familiar al debate teórico en América Latina, aunque en la práctica las tesis anti-utilitaristas sean simpáticas a muchos de los intelectuales de izquierda? De hecho, ese extrañamiento sociológico no es algo secundario sino el signo de un problema central del pensamiento sociológico en Latinoamérica. Se trata de la dificultad de este pensamiento para articular la crítica del capitalismo con una crítica más amplia de la cultura del eurocentrismo, mientras autores como K. Polanyi e M. Mauss habían avanzado en los elementos necesarios para el entendimiento del capitalismo como proyecto cultural.

Limitar la crítica del capitalismo a una lectura abstracta de la dominación del capital sobre el trabajo sin considerar las condiciones históricas y culturales concretas y particulares que dieron base a esta dominación, implica necesariamente olvidar parte de los fundamentos europeos de la colonialidad del poder y del saber. Como consecuencia, los sociólogos latinoamericanos, pasaron a incorporar la epistemología eurocéntrica para plantear la sociología de la modernización, sin comprender que ese era un modelo de gobernabilidad imaginado para asegurar la subalternidad. $\mathrm{O}$ sea, en América Latina, la reproducción de esta lectura limitada del capitalismo sin considerar los fundamentos de la colonialidad, ha significado la reproducción histórica de esquemas conceptuales inadecuados para comprender no únicamente el problema del capitalismo sino 
también de las diferencias culturales e históricas generadas por la dominación del capitalismo colonial.

Entonces respecto al entendimiento del utilitarismo en América Latina tenemos aquí una paradoja: por un lado, hay un sentimiento anti-utilitarista difuso y ampliado, pero innegable, en el interior de la sociología latinoamericana, que es sobre todo evidente en este momento de crisis del modelo de dominación eurocéntrico (WALLERSTEIN, 2007). Por otro lado, este sentimiento no está traducido en una crítica epistemológica que contribuya a explicar que el neoliberalismo no es un simple sistema de dominación de base económica sino sobre todo la expresión pragmática de una filosofía moral, el utilitarismo, que se produje como fetiche para justificar la explotación y el consumo ilimitado como esencias de la condición humana. Es importante registrar luego que la crítica económica aunque es importante, resulta insuficiente para alcanzar el corazón de la actividad capitalista, que es su razón moral.

Por otro lado, para hacer la critica a esa sociología de la modernización centrada en el progreso económico, los intelectuales descolonialistas necesitan necesariamente articular la crítica teórica tanto desde la denuncia de la exploración económica como desde la denuncia de la opresión moral y cultural. Es necesario comprender el sentido moral del utilitarismo para poder plantear una crítica más amplia que, bajo el deslizamiento epistémico de las modernidades mundiales, permita articular los cambios epistemológicos y epistémicos que ocurren simultáneamente en los dos lados de la modernidad.

\section{El utilitarismo como filosofía moral del capitalismo}

Otra pregunta para continuar: ¿Qué es, de hecho, el utilitarismo? De modo amplio, el utilitarismo es sobre todo la expresión de un sistema filosófico planteado desde las tradiciones empiristas e idealistas modernas y que tiene usos prácticos evidentes en la colonización planetaria, despreciando las diferencias, eliminando las alteridades y generando exclusiones para proponer el universalismo cultural europeo. El utilitarismo es una filosofía moral que valora la organización de la vida social a partir de los ideales de felicidad y 
buen vivir que se apoyan en criterios cuantitativos favorecidos por el cálculo racional. El utilitarismo es, luego, el modo dominante entre los modelos de inteligibilidad occidental, y constituye la base de las ideologías de la universalidad económica, del progreso histórico y de la uniformidad cultural planetaria. Su entendimiento, es necesario para el surgimiento de una sociología que integre los avances de la crítica anti-utilitarista y de la crítica descolonial en las zonas de contacto compartidas por las fuerzas cognitivas, políticas, morales y estéticas de las dos zonas de la modernidad planetaria.

En esta dirección, es necesario comprender en primer lugar, como lo propone M. Freitag (2009), que la filosofía utilitarista surge de las fisuras establecidas en la modernidad entre el apriorismo normativo kantiano de la libertad individual y la idea de totalidad social de Hegel. Para este autor canadiense, el utilitarismo filosófico hace una reducción de las ideas de Hegel y Kant para reforzar el empirismo positivista y la lectura de la ética como producto de la vocación egoísta del ser humano. En el utilitarismo filosófico, nos aclara Freitag, "la libertad subjetiva se presenta esencialmente bajo la forma empírica de la libertad de escoger y su expresión fenomenal es virtualmente racionalizada bajo la forma de un cálculo, partiendo del postulado de que esta libertad de escoger se realiza en un mundo o un ambiente objetivo donde todos los valores que justifican las finalidades de la acción son también reducidos a un denominador común" (FREITAG, 2009, p.3) ${ }^{3}$.

De manera amplia, A. Caillé, uno de los fundadores del M.A.U.S.S. (Movimiento Anti-utilitarista en las Ciencias Sociales), que es uno de los principales movimientos de renovación de la crítica teórica en Francia, ofrece una definición clara de esta idea al afirmar que "calificamos como utilitarista toda doctrina que re-

3 Según ciertos autores el utilitarismo no es una invención reciente; tiene sus raíces muy distantes, en la Grecia Antigua y en las obras de autores clásicos como Platón que en 'La República' buscaba definir la felicidad a partir de criterios cuantitativos (CAILLÉ, 2005: 203-240). Sin embargo, la obra ganó su expresión más elaborada en la modernidad, de las manos de filósofos ingleses como J. Benthan y J.S. Mill, derivando en un gran sistema ideológico con la expansión del mercantilismo eurocéntrico, una colonialidad de poder que contribuyó para la clasificación de la población mundial de acuerdo con la idea de raza, como nos explicaba Quijano (2005). 
posa sobre la afirmación de que los sujetos humanos son regidos por la lógica egoísta del cálculo de los placeres y penas, o aún, por el mero interés, y que es deseable que sea así pues no existe otro fundamento posible para las normas éticas distinto a la ley de la felicidad de los individuos o de las colectividades de individuos" (CAILLÉ, 1989: 17-18). Para este sociólogo francés, el utilitarismo se manifiesta de dos maneras: una positiva y otra normativa. La proposición positiva afirma que los hombres tienden a buscar el placer y a evitar el dolor y que ellos calculan sus acciones para llegar a este fin. La proposición normativa afirma que pueden ser cualificadas de justas y virtuosas las acciones que contribuyen al crecimiento de la felicidad de todos o del mayor número de personas (CAILLÉ, 1995, p.4-5). Este autor propone también una tipología de utilitarismos. Hay un utilitarismo vulgar que se preocupa con la felicidad individual y particularmente con los intereses materiales como lo más importante de todo; hay un utilitarismo científico que adapta este utilitarismo vulgar a las ciencias sociales y particularmente a las ciencias económicas; finalmente, hay un utilitarismo filosófico, inspirado en la filosofía moral inglesa, que integra al mismo tiempo el egoísmo y el altruismo cuando propone que lo más importante es la justicia social, así signifique el sacrificio de la felicidad individual (CAILLÉ, 2005, p.184).

¿Y cómo esa crítica anti-utilitarista reciente contribuye en el avance de la crítica descolonial en este momento presente? En mi opinión el debate anti-utilitarista ayuda a reconectar dos puntos: la crítica al proceso de mercantilización del mundo, de la vida que se hace clásicamente por la sociología europea, y la crítica epistemológica que se hace en el Sur. Esa crítica ampliada contribuye para evitar que la descolonización del planeta sea una tarea ilusoria que se hace desde el Sur y contra el Norte, como lo proponen los defensores de la ruptura epistemológica. En esa dirección, la crítica maussiana del utilitarismo se diferencia de la crítica sociológica anti-utilitarista tradicional por valorar una reflexión no desde modelos abstractos de la sociedad, sino desde las prácticas concretas, culturales e históricas (CAILLÉ, 2000; MARTINS, 2008). En esta dirección, la teoría del don, sistematizada por Mauss (2003) es una gran contribución por conectar el macro y el micro de la práctica social, incluyendo en 
esa visión de totalidad todos los elementos de la vida social, y no sólo los económicos. Tal crítica permite articular anti-utilitarismo y anti-colonialidad desde Europa con la finalidad de la fundación de una epistemología descolonial de la interioridad.

\section{La renovación de la crítica anti-utilitarista y su im- portancia para los estudios poscoloniales}

\section{La ilusoria universalidad del utilitarismo}

Descolonialidad y anti-utilitarismo caminan juntos. No creemos sin embargo que se pueda avanzar a fondo en el entendimiento de la colonialidad del saber y del poder en Latinoamérica, hoy, si no somos capaces de criticar la construcción moral utilitarista que se basa en la idea del egoísmo humano como motivación de vida y una verdad universal válida para todas las culturas y sociedades. De hecho, el ideal de universalidad fue un elemento del discurso colonizador y las tentativas de mercantilización del mundo a todo precio se basa en este fetiche de la universalidad de la cultura de consumo. La universalización del pensamiento mercantilista eurocéntrico funda la dominación capitalista planetaria por un saber etnocêntrico y excluyente que esconde jerarquías morales desiguales (DUSSEL, 2005; ESCOBAR, 2005; TAYLOR, 2005). Esas jerarquías ayudan a organizar una "sociedad burguesa de iguales" (Galcerán, 2010: 49) que valora desigualmente a los hombres por sus condiciones de género, de etnia y de origen geográfico ${ }^{4}$.

Desde la perspectiva anti-utilitarista, que emerge de la crítica al utilitarismo, no es la economía neoliberal, ciertamente, la asignatura científica hegemónica que puede inspirar los cambios necesarios en esta coyuntura de la crisis del sistema-mundo. Esto significaría que el neoliberalismo tendría que deconstruir la cultura mercadológica que fundamentó su sistematización doctrinaria lo

4 La sociedad burguesa valora la igualdad como condición de libertad de apropiación privada de los bienes materiales - las tierras, el trabajo productivo, los recursos sociales - y de los bienes simbólicos - los mecanismos de reconocimiento, los sueños y los deseos - por su uso privado y egoísta. 
que es una contradicción. Habría que incorporar la diversidad cultural, sobre todo los pueblos colonizados, que necesitan reorganizar sus memorias y saberes para que se presenten de modo coherente en su diversidad y en la construcción no sólo de una economíamundo, sino también de una modernidad-mundo participativa. El poder hegemónico no se deconstruye sólo desde su interior, sino desde una crítica que articule el interior y el exterior ${ }^{5}$.

Sin una discusión vertical sobre sus fundamentos morales, la crítica al neoliberalismo se percibe apenas como una manifestación superficial: la concentración de riquezas, la exclusión social y la desigualdad y la cultura de consumo. Así, es necesario trazar la conexión entre este modelo socio-histórico y cultural y los sistemas de dominación oligárquicos presentes particularmente en las sociedades poscoloniales para comprender los fundamentos del neoliberalismo como estrategia general de colonización planetaria, que se adapta a las realidades regionales por colonizadores locales (MEMMI, 2008). Este entendimiento del proceso colonial es decisivo para que empecemos con la deconstrucción crítica de los fundamentos históricos de la epistemología europea clásica y para anular los impactos morales negativos de la violencia epistémica colonial.

Este hecho nos lleva a comprender que son necesarios cambios importantes en la política y en la economía mundial, pero principalmente en los dispositivos cognitivos, estéticos y morales que sirven para agenciar los imaginarios de la modernización y del desarrollo. O sea, hay un avance efectivo en reacción al neoliberalismo como proyecto de exploración económica, pero poco se discuten en Latinoamérica sus fundamentos morales. Aquí, la crítica antiutilitarista, al interrogar las bases morales del neoliberalismo, esta produciendo un giro epistemológico significativo desde dentro.

5 Así, los mega-empresarios multinacionales y sus burocracias, condicionados por mentalidades excesivamente auto-referenciadas y delimitadas por la estructura de producción de lucros y privatizaciones, no tienen una visión amplia de los fundamentos sociales, políticos y morales de la crisis de regulación en curso. No tienen tampoco conciencia del surgimiento de una reacción social, cultural y política importante, nacida en las últimas décadas del embate cultural por la diferencia y la revaloración del lugar eco-comunitario. Los grupos dominantes solo privilegian una mirada desde el interior del proceso de dominación y no puede ser de otra forma. 
La contextualización del debate y el avance de la crítica al neoliberalismo

La crítica al capitalismo desde el Sur se basó, en general, en un esfuerzo de réplica de las directivas epistemológicas emanadas por el marxismo europeo, sin considerar seriamente la importancia del factor contexto para filtrar la recepción de las teorías exógenas. Por un largo periodo del siglo XX, la crítica anti-utilitarista en América Latina fue condicionada por los límites disciplinarios y cognitivos generados por la asimilación de ideas europeas sin considerar seriamente las diferencias de contextos históricos que legitiman y condicionan las creencias teóricas, incluso las creencias marxistas. Hubo, claro, esfuerzos de avance en cuestionamientos más profundos si pensamos en el trabajo de Mariátegui, con la adaptación del marxismo a la realidad peruana, o de Gilberto Freyre, con la adaptación de la antropología cultural a la realidad de los trópicos brasileños. Pero tales contribuciones no fueron suficientemente fuertes para una reacción anti-utilitarista que integrase en la praxis política dos factores centrales: los roles de las creencias y tradiciones locales respecto a otra epistemología, por un lado, y el impacto de la violencia epistémica del proceso colonizador sobre la consciencia crítica de los colonizados, por el otro.

La reducción de la discusión capitalista pos-colonial a la explotación económica es importante pero teóricamente insuficiente y epistemológicamente estrecha. Los rumbos problemáticos de la reacción política y cultural al capitalismo en el siglo XX en América Latina lo prueban. El balance de los movimientos sociales indica, al contrario, que una crítica enriquecida es necesaria para articular esta reflexion del capitalismo con la praxis de los movimientos sociales y activistas, y para eso es decisivo el rol de tecnologías de traducción que son necesarias por la contextualización teórica de ideas y experiencias. La lucha por la propiedad de los bienes de producción y de vida y contra la explotación del trabajo, central en la crítica marxista, no basta para el avance de la formación de una nueva praxis. Las luchas de los oprimidos no son una operación de movilización política mecánica ofrecida por la existencia misma de la pobreza. Sin embargo, tales luchas exigen una contextualización de la operación de traducción, que es un "esfuerzo de reforzar las 
convergencias y sinergias a partir de la diversidad, a partir de un impulso contra-hegemónico" (CAIRO y BRINGEL, 2010, p. 36).

En la perspectiva poscolonial, constatamos que la colonización provocada por el capitalismo no tuvo sólo efectos materiales en términos de beneficios económicos, porque además provocó procesos de devaluación moral y cultural importantes y de destrucción de las dignidades de comunidades diversas en África, Asia y América. Así, la superación del sentimiento de inferioridad producido por la violencia epistémica sobre las poblaciones locales colonizadas es un factor decisivo para la reacción anticapitalista, antes y ahora. Y la contextualización de ideas y prácticas y su recepción por parte de los colonizados es una exigencia epistemológica central para poder interpretar la naturaleza de las reacciones en curso en América Latina.

En esta dirección, la revisión del pensamiento clásico, incluyendo el marxismo, por parte de los intelectuales anti-utilitaristas europeos en este momento (REVUE DU MAUSS, 2009), prueba la importancia del elemento de la contextualización como dispositivo simbólico de traducción entre narrativas producidas en diversas situaciones geográficas y en situaciones temporales variadas y distintas de las européas. En situación de colonialidad la crítica social debe considerar igualmente, al lado de los aspectos económicos, otros factores relativos a los modos particulares de organización del poder, del ejercicio de la dominación, de organización de lo político y de las prácticas culturales. Se tendrían que considerar principalmente las modalidades mediante las cuales la jerarquía de dominación colonial contribuye a violentar y destruir las culturas locales y a alienar a las poblaciones de los territorios colonizados. Es decir, tenemos que hacer simultáneamente la crítica de la dominación colonial y la critica anti-utilitarista, en diálogo permanente con los campos humanistas europeos, norteamericanos y con otros centros que están articulando una revisión importante de la violencia epistémica colonial como, por ejemplo, India ${ }^{6}$.

6 En las condiciones de colonialidad la crítica del capitalismo debe incluir también otro punto: la dependencia mitológica de los intelectuales del Sur con relación a los del Norte. Esa dependencia contribuye a que las ideas sean asimiladas acríticamente sin consideración efectiva sobre los usos de esas prácticas teóricas para explicar la praxis de los movimientos sociales y culturales y los 
Así, la crítica poscolonial debe considerar la importancia del aporte anti-utilitarista para el avance de la teoría crítica del capitalismo contemporáneo y de la colonización eurocéntrica, permitiendo el surgimiento de una nueva cartografía de saber, de carácter transnacional, abierto y en doble vía. Tales procesos comprensivos, teóricos, morales y tecnológicos son indispensables para repensar los límites de la globalización. La profundización de esta discusión sobre la nueva teoría crítica, pone de inmediato, riesgos teóricos y prácticos respecto a una nueva ambivalencia constitutiva del trabajo sociológico que se expresa, por un lado, por la complejidad cultural, psicológica y política de la sociedad civil y, por otro, esa ambivalencia revela la fuerza de los procesos de individuación que están provocando fuertes reorganizaciones de los movimientos sociales desde las periferias. Esas reorganizaciones de las luchas se abren en estructuras reticulares y creativas como las redes sociales (SCHEREN WARREN, 2008; BRINGEL y ECHART, 2009), provocando el nacimiento de prácticas colaborativas inéditas que significan la valoración de lo social por el individuo (ARNOLD-CHATALIFAUD, TYUMALA y URQUIZA, 2007); ellas cuestionan el sentido de la política nacional para incorporar desafíos típicos de los espacios transnacionales.

\section{Articulando la reacción anti-utilitarista y la posco- lonialidad: puntos para el debate}

Para señalar la articulación adecuada de las contribuciones de la crítica anti-utilitarista para los estudios poscoloniales en este momento y pensando también en el avance de la crítica a los modelos de desarrollo que perpetúan los esquemas de dominación capitalista y colonial, es importante fijar ciertos puntos del debate como marcos de reconocimiento:

a) El reconocimiento de la emergencia de una nueva epistemología del conocimiento ampliada, anti-utilitarista y descolonial,

desafíos de la acción pedagógica y mediadora. La dependencia refleja también el efecto de la violencia epistémica en el plano de la producción intelectual, simbólica y cultural. 
tiene que considerar igualmente la importancia de la crítica desde dentro y desde fuera, desde el Norte y desde el Sur

Debemos reconocer que la crítica poscolonial no puede obviamente descontruir teóricamente el modelo neoliberal desde el interior, pues nos falta el sentimiento y los recuerdos de la vida del ciudadano en la cultura de los que viven en las sociedades colonizadoras. Considerando así, por ejemplo, la vivencia de ciertas experiencias como el significado histórico del movimiento obrero y de la lucha de la izquierda intelectual europea, por un lado, y la sobrevivencia de los europeos a las grandes guerras y al nazismo, por otro, tenemos que aceptar la posibilidad de una crítica teórica al capitalismo desde dentro, desde Europa, y cuya dimensión histórica no es fácilmente entendida desde fuera.

En la dirección contraria, le falta a la crítica anti-utilitarista europea la memoria de lo que significó la violencia política y moral de la colonización sobre las estructuras simbólicas y culturales de las comunidades de origen en las áreas ocupadas por el proceso colonizador, lo que es decisivo por la crítica desde fuera. En esta dirección, la crítica sociológica no puede limitarse a ser anti-utilitarista, debiendo incorporar la experiencia de la colonialidad. Este vacio teórico es una contradicción si consideramos que la sociología nació y se desarrolló como un proyecto anti-utilitarista y anti-reduccionista, pero no como crítica de la colonialidad. Así, la sociología debe abrirse para una crítica anti-utilitarista que valore la práctica de lo cotidiano y de los cambios no-económicos como los afectivos y lúdicos, lo que es posible por el sistema del don, o sea, del donar-recibir-retribuir (MAUSS, 2003; CAILLÉ, 2000; MARTINS, 2008). Esta apertura de la crítica anti-utilitarista sobre el cotidiano expresa necesariamente la diversidad de experiencias e impone el juego de traducciones entre actores diversos en las fronteras transnacionales.

Desde las exterioridades, la crítica de frontera al utilitarismo privilegia los efectos caóticos que el modelo neoliberal produce sobre las instituciones sociales y culturales en general y sobre las de América Latina en particular. Desde el interior del modelo europeo, esta crítica ilumina el carácter etnocéntrico e históricamente 
localizado del neoliberalismo, para demostrar que las tentativas de universalizar la economía de mercado como institución universal son un equívoco teórico con importantes perjuicios prácticos (MARTINS, 2008, 2009a, 2009b). Por eso, es necesario articular los campos de conocimiento geográficos en un campo pos-geográfico de manera a permitir una crítica del Estado colonial desde otros territorios de conocimiento y de producción de la crítica sociológica. Sin esa tarea política y cultural la teoría poscolonial no va a lograr integrar con efectividad la importancia de la crítica anti-utilitarista en temas como progreso, desarrollo, ilimitación, crecimiento (LATOUCHE, 2009).

b) El reconocimiento que la critica anti-utilitarista en Europa pasa a ser un proyecto descolonial cuando contestó el pensamiento monológico estructuralista para proponer una ampliación de la idea de sociedad que interroga el eurocentrismo

Es importante considerar en este registro que las reacciones anti-utilitaristas en Europa no fueron producto solamente de utopías, sino también de heterotopías, de creencias e ideas no previstas en el imaginario moderno occidental. El sueño de otra vida y de otro mundo está en la base de la crítica anticapitalista presente en el movimiento obrero, en el movimiento feminista y en todas las movilizaciones sociales y culturales importantes en los dos últimos siglos en Europa que cuestionan la naturaleza antropocéntrica y patriarcal del modelo colonial. Debemos, pues, comprender que dentro del imaginario hegemónico del Norte y a lo largo del siglo $\mathrm{XX}$, hay resistencias exitosas que son espejos para la construcción de la crítica mundial intercultural, pos-colonial y anti-utilitarista. De la misma manera, debemos recordar que las luchas anticoloniales no fueron desarrolladas contra la cultura europea desde afuera sino en contacto con ella, como nos enseñan intelectuales sensibles como F. Fanon (1975), médico francés negro que vivió en Argelia o A. Memmi (2008), intelectual tunecino que vivió en Francia.

c) El reconocimiento de la importancia de los espacios transnacionales para las nuevas movilizaciones sociales y culturales, articulando Norte y Sur por nuevas tecnologías de traducción que impactan sobre las ideas y las prácticas 
Hasta ahora los giros epistemológicos del Sur y del Norte estaban condicionados, por un lado por el proceso de colonización planetario, que subordinaba el Sur al Norte; y por el otro, la dependencia de los campos de conocimiento de la realidades nacionales que constituían también un obstáculo para la integración de los saberes. Un nuevo y más amplio giro epistemológico en términos de pos-colonialidad debe aparecer necesariamente como base de nuevos territorios transnacionales (MATO, 2002; CAIRO y BRINGEL, 2010). Así, hay reacciones diversas en curso que revelan la ampliación de la consciencia espacial de los actores, intelectuales y militantes, desde una situación al mismo tiempo poscolonial y anti-utilitarista. Esta simultaneidad no es casual, pero refleja la complejidad de los nuevos dispositivos tecnológicos de construcción del conocimiento a nivel mundial, entre ellos, por ejemplo, la internet y las redes virtuales y presenciales.

La revaloración del lugar concebido ya no sólo como tradición resistente sino como experiencias complejas en las fronteras de lo público y lo privado, de lo local y lo global, de lo nacional y lo internacional, de la sociedad y la naturaleza, pasó a asumir la forma de nuevos conocimientos locales anclados en la práctica glocal que constituye la semilla para cuestionar el mito del desarrollo eurocéntrico y los fundamentos universales de la globalización capitalista. Experiencias como la del movimiento zapatista en México (FORERO y GARCIA, 2007), la de los pueblos indígenas en Ecuador (DÁVILA, 2003) y la de los Sem-Terra en Brasil (GOHN, 2003 y 2008) son expresiones de formas de acciones colectivas que resisten a la uniformización espacial generada por el capitalismo, recreando nuevas modalidades diferenciadas de organización cultural y política.

Finalmente, es necesario que se esclarezcan las condiciones para profundizar el giro epistemológico iniciado por las teorías poscoloniales, para resignificar más claramente los embates culturales en torno a la reorganización de los lugares ecocomunitarios. Ésta es una exigencia de praxis teórica importante para permitir que los intelectuales, activistas y mediadores de redes se desprendan de meros discursos emocionales generados como reacción al capitalismo, que son legítimos en términos del sentido común, 
pero insuficientes en el plano científico y político. La nueva praxis teórica debe establecer los caminos de la deconstrucción del pensamiento hegemónico con vistas a la reconstrucción de un discurso más complejo, plural y contextualizado sobre la globalización, la modernización, la democracia y la gestión pública.

Recebido em: 24.9.2010

Aprovado em: 30.11 .2010

\section{Referencias}

ARNOLD-CHATALIFAUD, M.; TYUMALA, D.; URQUIZA, A. Colaboración, cultura y desarrollo: entre el individualismo y la solidariedad organizada In: ARNOLD-CHATALIFAUD, M. \& TYUMALA, D. Colaboración, cultura y desarrollo. Santiago: Edicións MADFuncación Soles, 2007.

BHABHA, H. O local da cultura. Belo Horizonte: Editora da UFMG;Breton, D. Adeus ao corpo: antropologia e sociedade. São Paulo: Papirus, 2003.

BRINGEL, B. \& ECHART, E. Movimentos sociais e democracia: os dois lados das "fronteiras" In Bringel e Espiñeira (Orgs.) Caderno CRH 54 Dossiê: Movimentos sociais e política. V.21, n.54, set.-dez, 2009.

CAILLÉ, A. Critique de la raison utilitaire: Manifeste du MAUSS, Paris: Agalma/La Découverte, 1989.

. Présentation. In: Revue du MAUSS semestrelle: Qu'est ce que c'est que l'utilitarisme? Une enigme dans l'histoire des idées, n.6, 2. Semestre, 1995.

de Brouwer, 2000.

. L'anthropologie du don: le tiers paradigme. Paris : Desclée

. Don, intérêt et désintéressement: Bourdieu, Mauss, Platon et quelques d'autres, Paris: La Découverte/MAUSS, 2005.

CAIRO, H. \& BRINGEL, B. Articulaciones del Sur global: afinidad cultural, internacionalismo solidário y iberolatinoamericano en la globalización contrahegemónica In: CAIRO, E. y GROSFOGUEL, R. (et. al.) Descolonizar la modernidad, descolonizar Europa: un diálogo Europa-América. Madrid: IEPALA, 2010. 
DÁVILA, F.R. Estado y movimientos étnicos en Ecuador. In: SEONE, J. (Compilador) Movimientos sociales y conflicto en América Latina. Buenos Aires: CLACSO, 2003.

DERRIDA, J. L'écriture et la différence. Paris: Editions du Seuil, 1967. DERRIDA, J., LACLAU, E. \& MOUFFE, C. Desconstruction and pragmatisme. Routledege: USA, 1996.

DUSSEL, E. Europa, modernidade e eurocentrismo. In: LANDER, E. (Org.) A Colonialidade do saber: eurocentrismo e ciências sociais. Perspectivas latinoamericanas. Buenos Aires: CLACSO, 2005.

ESCOBAR, A. O lugar da natureza e a natureza do lugar: globalização ou pós-desenvolvimento? In: LANDER, E. (Org.) A colonialidade do saber: eurocentrismo e ciências sociais. Perspectivas latinoamericanas. Buenos Aires: CLACSO, 2005.

FANON, F. Pele negra, máscaras brancas. Porto: Paisagem, 1975.

FORERO, E.S. \& GARCÍA, E.G. La resistencia pacífica del EZLN en tiempos de globalización In Telleschi, T. y Carero y Forero, E.A.S. (Coords.) Espacio y tiempo en la globalización: Una visión de la transparencia en la información. Universitá de Piza/ Comisión Estatal para el acceso a la información Pública del Estado de Sinaloa-México, 2007.

FREITAG, M. Symbolisme et reconnaissance: Au dela de l'holisme et individualisme In: Revue du MAUSS Permanent [http://www. journaldumauss.net], 2009.

GALCERÁN, M. Límites y paradojas de los universales eurocêntricos. In: GOLDNER, A. (1989) Pour une sociologie réflexive In: Revue du Mauss, n.4, 2. Semestre, p.11-26, 2010.

GOHN, M.G. Movimentos sociais no início do século XXI: antigos e novos atores sociais. Petrópolis: Editora Vozes, 2003.

. Abordagem teórica no estudo dos movimentos sociais na América Latina. In: BRINGEL \& ESPIÑEIRA (Orgs.) Caderno CRH 54 Dossiê: Movimentos sociais e política. V.21, n.54, set.-dez, 2008.

GROSFOGUEL, R. Descolonizar los uni-versalismos occidentales: el pluri-versalismo transmoderno decolonial de Aimé Cesaire a los zapatistas In: CAIRO, E.; GROSFOGUEL, R. (et al.) Descolonizar la modernidad, descolonizar Europa: un diálogo Europa-América. Madrid: IEPALA, 2010. 
HALL, S. A identidade cultural na pós-modernidade. 2a . Edição, Rio de Janeiro: DP\&A, 1992.

. Da diáspora: Identidades e mediações culturais. Belo Horizonte: Editora da UFMG, 2003.

KRAMSCH, O. Dans le balon rouge? Entre el proyecto modernidad/ colonialidad latinoamericano y la Europa fronteriza realmente existente. In: CAIRO, E. \& GROSFOGUEL, R. (et al.) Descolonizar la modernidad, descolonizar Europa: un diálogo Europa-América. Madrid: IEPALA, 2010.

LATOUCHE, S. La decroissance comme projet politique de gauche. In: Revue du MAUSS, n.34, 2009.

MARTINS, P.H. De Lévi-Strauss a MAUSS - Movimento AntiUtilitarista nas Ciências Sociais: itinerários do dom. In: Revista Brasileira de Ciências Sociais, v.23, p. 105-130, 2008.

. Reterritorialización, nuevos movimientos sociales y democracia participativa en el cotidiano de América Latina. In: Revista Convergencia. Toluca (México), vol. 51, p. 17-44, 2009a.

. Redes Sociais: ente o simplismo da ideologia utilitarista e a complexidade das mudanças sócio-históricas contemporâneas. In: MARTINS \& MEDEIROS. (Orgs.) América Latina e Brasil em Perspectiva: debates do Pré-Alas Recife. ALAS/Editora da UFPE, 2009b.

MATO, D. Estudios y otras prácticas intelectuales latinoamericanas en cultura y poder. In: D. Mato (Coord.) Estudios y otras prácticas intelectuales latinoamericanas en cultura y poder. Caracas: FLACSO/ Universidad Central de la Venezuela, 2002.

MAUSS, M. Sociologia e antropologia. São Paulo: Cosac \& Naify, 2003.

MEMMI, A. Retrato do colonizado precedido de retrato do colonizador. Rio de Janeiro: Civilização Brasileira, 2008.

MIGNOLO, W. Desobediência epistêmica: a opção descolonial e o significado de identidade em política. In: Cadernos de Letras da UFF - Dossiê: Literatura, língua e identidade, no 34, p. 287-324, 2008.

QUIJANO, A. Colonialidad del poder, eurocentrismo y América Latina. In: LANDER, E. (Org.). A colonialidade do saber: eurocentrismo 
e ciências sociais. Perspectivas latinoamericanas. Buenos Aires: Clacso, 2005.

REVUE DU MAUSS. Que faire, que penser de Marx aujourd'hui? N. 34, segundo semiestre, 2009.

SANTOS, B.S. A gramática do tempo: para uma nova cultura política. São Paulo: Cortez, 2008.

SCHERER-WARREN, I. Redes de movimentos sociais na América Latina - caminhos para uma política emancipatória In: Bringel e Espiñeira (Orgs.) Caderno CRH 54 Dossiê: Movimentos sociais e política. V.21, n.54, set.-dez, 2008.

TAYLOR, C. As fontes do self: a construção da identidade moderna. São Paulo: Edições Loyola, 2005.

WALLERSTEIN, I. O universalismo europeu: a retórica do poder. São Paulo: BoiTempo, 2007.

\begin{abstract}
Anti-utilitarian critique in the North and its importance for advancing post-colonial thought in societies of the South

The reflections we carry out in this article are based on two complementary theses: one which is epistemological and the other, epistemic. The epistemological thesis proposes a close connection between post-colonial and de-colonializing studies - which seek to revalue the traditions, struggles and socio-historic possibilities of the societies of the South -, and the anti-utilitarian studies that provide a critique of neo-liberalism and the commodification of the world that has been promoted by the societies of the North. The epistemic thesis, in turn, suggests that the advance of critical theory over the last decades in both South and North has been produced by the progressive and increasingly accelerated dislocation of the imaginary of modernity, as it is pushed from a Eurocentric view toward one which looks at the entire world.
\end{abstract}

Keywords: post-coloniality, de-colonization, anti-utilitarianism, sociology. 
